Pulse-chase experiments and immunoprecipitations. For pulse-chase experiments, $2.5 A_{600}$ cells were taken from a logarithmically growing culture for each time point and were labelled with $62.5 \mu \mathrm{Ci}\left[{ }^{35} \mathrm{~S}\right]$-methionine. Growth, labelling, chase conditions and other experimental procedures, such as cell lysis, immunoprecipitation and SDS-PAGE, were performed as described ${ }^{13}$.

Deglycosylation experiments and western analysis. Cells were grown at the indicated temperature in complete synthetic medium containing $2 \%$ glucose to an $A_{600}$ of 3.0. Immunoprecipitation and deglycosylation of CPY* was performed as described ${ }^{5}$. Immunoprecipitated material was boiled in $50 \mu$ l UREA buffer before SDS-PAGE using a $8 \%$ gel and blotting. For western analysis, detection of the indicated proteins was performed using the respective antibodies.

Protease protection experiments. Spheroplasting and cell breakage were done as described ${ }^{5}$. For protease treatment of the pellet, trypsin was added to a final concentration of $0.5 \mathrm{mg} \mathrm{ml}^{-1}$ after resuspension of the pellet. The samples were incubated for $30 \mathrm{~min}$ on ice. If added, Triton X-100 was present at $1 \%$. All treatments were stopped by TCA precipitation. After resuspending the pellet in $100 \mu$ l UREA buffer, CPY* was analysed by SDS-PAGE and immunoblotting. $\boldsymbol{\beta}$-Galactosidase activity test. After adding cycloheximide to a final concentration of $0.5 \mathrm{mg} \mathrm{ml}^{-1}$ at zero time $(t=0)$ to the logarithmically growing culture, $0.3 A_{600}$ of cells were taken for each time point, mixed with lysis buffer $(0.6 \%$ Triton X-100, $0.75 \%$ ONPG, $2.25 \% \beta$-ME, $0.15 \mathrm{M}$ Tris- $\mathrm{BCl}, \mathrm{pH} 7.5)$ and kept at $-80^{\circ} \mathrm{C}$ for $30 \mathrm{~min}$. After incubation for $60-90 \mathrm{~min}$ at $37^{\circ} \mathrm{C}, 75 \mu \mathrm{l}$ of $1 \mathrm{M}$ $\mathrm{NaHCO}_{3}$ was added to the samples, debris was removed by centrifugation $(20,000 \mathrm{~g}, 3 \mathrm{~min})$ and $A_{405}$ was determined.

Received 14 July; accepted 31 July 1997

1. Pryer, N. K., Wuestehube, L. J. \& Schekman, R. Vesicle-mediated protein sorting. Annu. Rev. Biochem. 61, 471-516 (1992)

2. Gething, M. J. \& Sambrook, J. Protein folding in the cell. Nature 355, 33-45 (1992).

3. Kopito, R. R. ER quality control: the cytoplasmic connection. Cell 88, 427-430 (1997).

4. Biederer, T., Volkwein, C. \& Sommer, T. Degradation of subunits of the Sec6lp complex, an integral component of the ER membrane, by the ubiquitin-proteasome pathway. EMBO J. 15, 2069-2076 (1996).

. Hiller, M. M., Finger, A., Schweiger, M. \& Wolf, D. H. ER degradation of a misfolded luminal protein by the cytosolic ubiquitin-proteasome pathway. Science 273, 1725-1728 (1996).

6. Werner, E. D., Brodsky, J. L. \& McCracken, A. A. Proteasome-dependent endoplasmic reticulumassociated protein degradation: an unconventional route to a familiar fate. Proc. Natl Acad. Sci. USA 93, 13797-13801 (1996).

Jensen, T. J. et al. Multiple proteolytic systems, including the proteasome, contribute to CFTR processing. Cell 83, 129-135 (1995)

8. Halaban, R. et al. Aberrant retention of tyrosinase in the endoplasmic reticulum mediates accelerated degradation of the enzyme and contributes to the dedifferentiated phenotype of amelanotic melanoma cells. Proc. Natl Acad. Sci. USA 94, 6210-6215 (1997).

9. Walter, P. \& Johnson, A. E. Signal sequence recognition and protein targeting to the endoplasmic reticulum membrane. Annu. Rev. Cell Biol. 10, 87-119 (1994).

10. Rapoport, T. A., Jungnickel, B. \& Kutay, U. Protein transport across the eukaryotic endoplasmic reticulum and bacterial inner membranes. Annu. Rev. Biochem. 65, 271-303 (1996).

11. Wiertz, E. J. H. J. et al. Sec61-mediated transfer of a membrane protein from the endoplasmic reticulum to the proteasome for destruction. Nature 384, 432-438 (1996).

12. Lyman, S. K. \& Schekman, R. Binding of secretory precursor polypeptides to a translocon subcomplex is regulated by BiP. Cell 88, 85-96 (1997).

13. Finger, A., Knop, M. \& Wolf, D. H. Analysis of two mutated vacuolar proteins reveals a degradation pathway in the endoplasmic reticulum or a related compartment of yeast. Eur. J. Biochem. 218, 565574 (1993).

14. Stirling, C. S., Rothblatt, J., Hosobuchi, M., Deshaies, R. \& Schekman, R. Protein translocation mutants defective in the insertion of integral membrane proteins into the endoplasmic reticulum. Mol. Cell. Biol. 3, 129-142 (1992).

15. Panzner, S., Dreier, L., Hartmann, E., Kostka, S. \& Rapoport, T. A. Posttranslational protein transport in yeast reconstituted with a purified complex of Sec proteins and Kar2p. Cell 81, 561-570 (1995).

16. Finke, K. et al. A second trimeric complex containing homologs of the Sec61p complex functions in protein transport across the ER membrane of S. cerevisiae. EMBO J. 15, 1482-1494 (1996).

17. Feldheim, D., Rothblatt, J. \& Schekman, R. Topology and functional domains of Sec63p, an endoplasmic reticulum membrane protein required for secretory protein translocation. Mol. Cell. Biol. 12, 3288-3296 (1992).

18. Corsi, A. K. \& Schekman, R. The lumenal domain of Sec63p stimulates the ATPase activity of BiP and mediates BiP recruitment to the translocon in Saccharomyces cerevisiae. J. Cell Biol. 137, 1483-1493 (1997).

19. Cyr, D. M., Langer, T. \& Douglas, M. G. DnaJ-like proteins: molecular chaperones and specific regulators of Hsp70. Trends Biochem. Sci. 19, 176-181 (1994).

20. Hanein, D. et al. Oligomeric rings of the Sec61p complex induced by ligands required for protein translocation. Cell 87, 721-732 (1996).

21. Scidmore, M. A., Okamura, H. H. \& Rose, M. D. Genetic interactions between KAR2 and SEC63, encoding eukaryotic homologues of DnaK and DnaJ in the endoplasmic reticulum. Mol. Biol. Cell 4, $1145-1159$ (1993).

22. Sanders, S. L., Whitfield, K. M., Vogel, J. P., Rose, M. D. \& Schekman, R. Sec6lp and BiP directly facilitate polypeptide translocation into the ER. Cell 69, 353-365 (1992).

23. Esnault, Y., Blondel, M.-O., Deshaies, R. J., Schekman, R. \& Képès, F. The yeast SSS1 gene is essential for secretory protein translocation and encodes a conserved protein of the endoplasmic reticulum. EMBO J. 12, 4083-4093 (1993).

24. Ng, D. T., Brown, J. D. \& Walter, P. Signal sequences specify the targeting route to the endoplasmic reticulum membrane. J. Cell Biol. 134, 269-278 (1996).
25. Chen, P., Johnson, P., Sommer, T., Jentsch, S. \& Hochstrasser, M. Multiple ubiquitin-conjugating enzymes participate in the in vivo degradation of the yeast MAT $\alpha 2$ repressor. Cell 74, 357-369 (1993). 26. Knop, M., Finger, A., Braun, T., Hellmuth, K. \& Wolf, D. H. Derl, a novel protein specifically requires for endoplasmic reticulum degradation in yeast. EMBO J. 15, 753-763 (1996).

27. Hampton, R. Y., Gardner, R. G. \& Rine, J. Role of $26 \mathrm{~S}$ proteasome and HRD genes in the degradation of 3-hydroxy-3-methylglutaryl-CoA reductase, an integral endoplasmic reticulum membrane protein. Mol. Biol. Cell 7, 2029-2044 (1994).

28. Ausubel, F. M. et al. Current Protocols in Molecular Biology (Greene, New York, 1992).

29. Rose, M. D., Misra, L. M. \& Vogel, J. P. Kar2, a karyogamy gene, is the yeast homolog of the mammalian BiP/GRP78 gene. Cell 57, 1211-1221 (1989).

Acknowledgements. We thank M. Hochstrasser (Deg1- $\beta$-galactosidase fusion), M. D. Rose (kar2-113 allele), T. A. Rapoport (Sec61p antibodies), H. K. Rudolph and R. Schekman (Kar2 antibodies), M. Knop (polyclonal CPY antibodies) and S. Rupp (proteinase yscA antibodies) for providing gene constructs and affinity purified antibodies; and S. Jäger and M. Hämmerle for discussions. This work was supported by the Bundesministerium für Forschung und Technologie and the Fonds der Chemischen Industrie, Frankfurt.

Correspondence and requests for materials should be addressed to D.H.W. (e-mail: dieter.wolf@po.unistuttgart.de).

\section{Marking of active genes on mitotic chromosomes}

\section{Emil F. Michelotti ${ }^{\star}$, Suzanne Sanford \& David Levens}

Gene Regulation Section, Laboratory of Pathology, National Cancer Institute, National Institutes of Health, Building 10, Room 2N105, Bethesda, Maryland 20892, USA

During development and differentiation, cellular phenotypes are stably propagated through numerous cell divisions ${ }^{1}$. This epigenetic 'cell memory' helps to maintain stable patterns of gene expression $^{2}$. DNA methylation ${ }^{3}$ and the propagation of specific chromatin structures may both contribute to cell memory ${ }^{4}$. There are two impediments during the cell cycle that can hinder the inheritance of specific chromatin configurations: first, the pertinent structures must endure the passage of DNA-replication forks in $S$ phase ${ }^{5}$; second, the chromatin state must survive mitosis, when chromatin condenses, transcription is turned off, and almost all double-stranded DNA-binding proteins are displaced $^{6,7}$. After mitosis, the previous pattern of expressed and silent genes must be restored. This restoration might be governed by mass action, determined by the binding affinities and concentrations of individual components. Alternatively, a subset of factors might remain bound to mitotic chromosomes, providing a molecular bookmark to direct proper chromatin reassembly. Here we analyse DNA at transcription start sites during mitosis in vivo and find that it is conformationally distorted in genes scheduled for reactivation but is undistorted in repressed genes. These protein-dependent conformational perturbations could help to re-establish transcription after mitosis by 'marking' genes for re-expression.

DNase I-hypersensitive sites in chromatin are useful indicators of gene activity and may persist during mitosis, despite cessation of transcription and dissociation of most transcription factors from mitotic chromosomes. ${ }^{6}$. Many DNase I-hypersensitive sites are also sensitive to S1 nuclease and hence may have single-stranded features ${ }^{8-10}$. Melted regions of the human $c-m y c$ gene have been mapped in unsynchronized cells and shown to bind transcription factors in vitro ${ }^{10,11}$. During mitosis, the single-stranded properties of chromatin increase $\sim 10$-fold ${ }^{12}$. To test whether any mitosis-specific increase in single-stranded character might occur in previously characterized S1-sensitive regions of the human c-myc gene, bases reactive to potassium permanganate ${ }^{10,11}$ were mapped by using ligation-mediated polymerase chain reaction (LM-PCR). Factors binding to such melted regions during mitosis may contribute to the inheritance of the $\mathrm{c}-m y c$ gene chromatin structure through this

^Present address: Genelabs Technologies, 505 Penobscot Drive, Redwood City, California 94043, USA 
$\mathbf{a}$

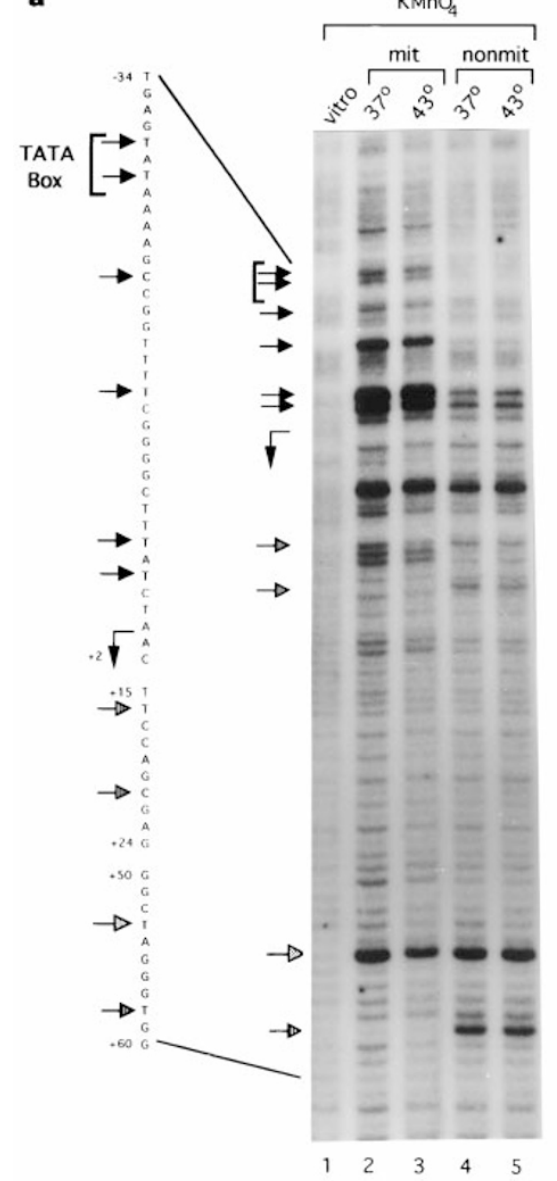

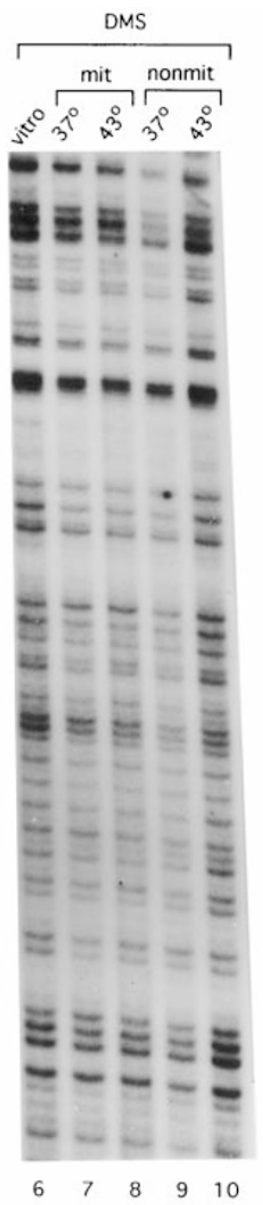

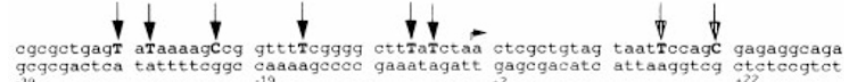
gcgegactca tattttogge caaaagecco gaaatagatt gagegacate attaaggteg ctetcogtct $\frac{1}{\nabla} \phi$ gggagegage gggeggecgg oragggrgga agagecggge
ccotegeteg cocgceggec gatcccacct totoggececg
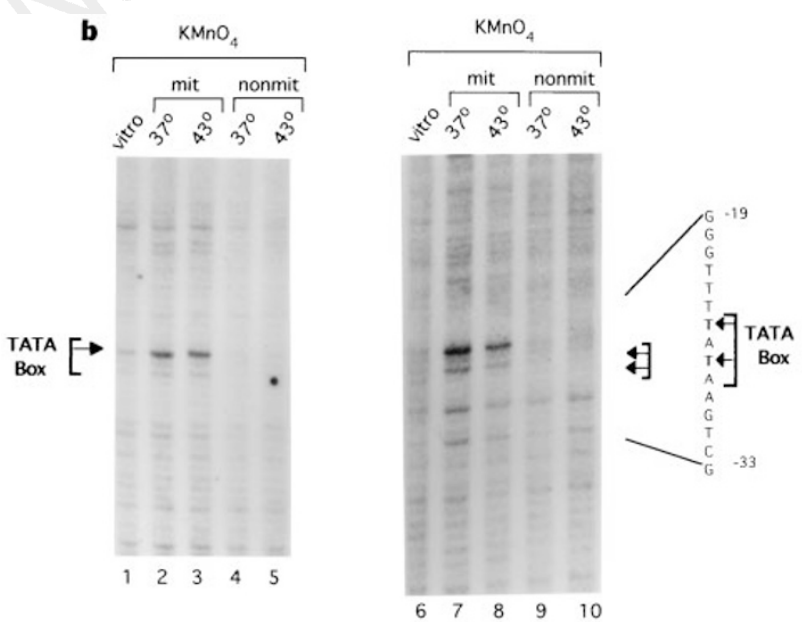

$$
\text { Spl }
$$

VGtctc cgtgacgact

ataaaccc caggggcaag cggtccggat aacggctagc $-48$ c
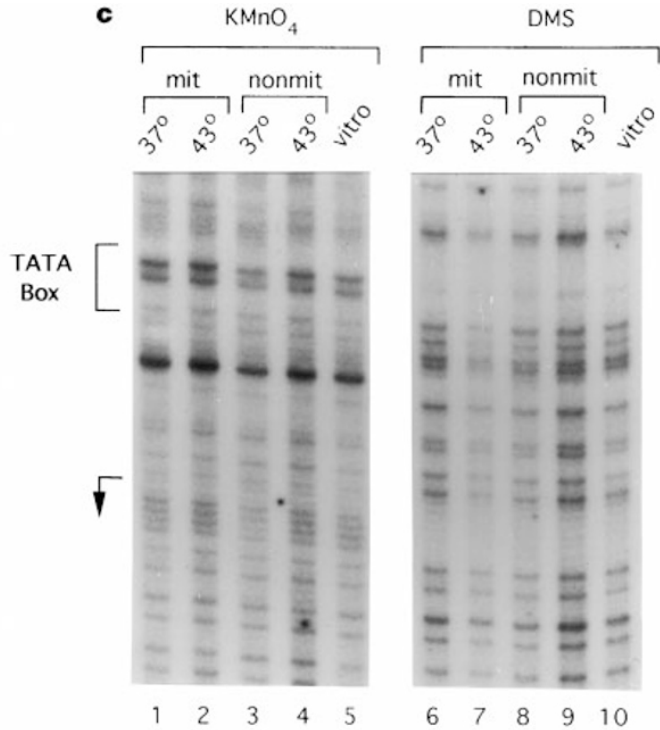

TATA box

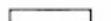

ccggccett ataatgcgag ggtctggacg getgaggacc cccgagctgt ggccgggaaa tattacgctc ccagacctgc cgactcctgg gggctcgaca $-27$ d
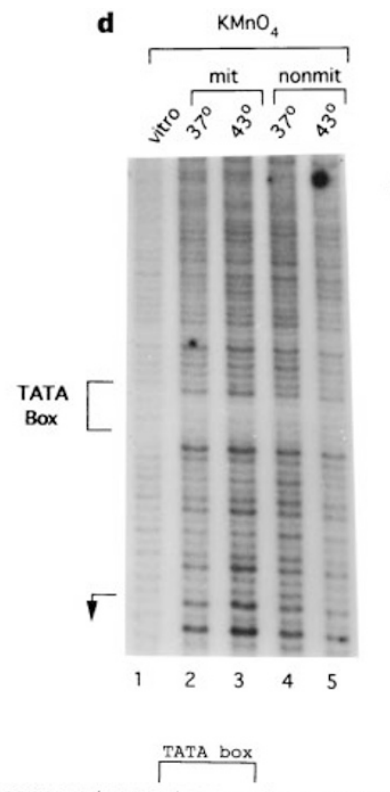

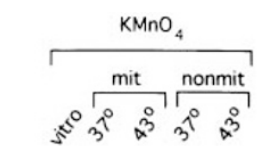

4

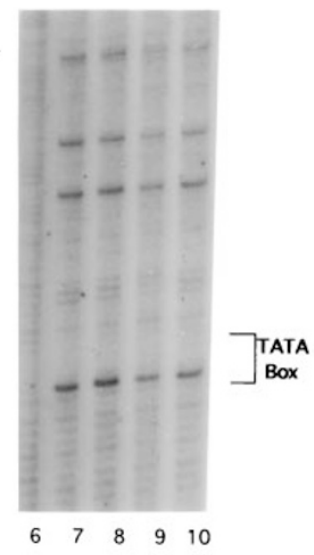

gagccaggge tgggcataaa agtcagggca gagcctcta ttgcttacat ttgcttctga

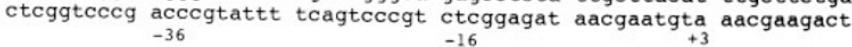

Figure 1 Conformational distortion of the TATA-box region of the c-myc, hsp70, and $\beta$-globin genes is mitosis-specific and correlates with expression. LM-PCR analysis of $\mathbf{a}$, c-myc P2 promoter, top strand; $\mathbf{b}$, hsp70 promoter; c, c-myc P1 promoter, top strand; $\mathbf{d}, \beta$-globin promoter. Included are summaries of sequences and hypersensitivities: solid arrows indicate sites of $\mathrm{KMnO}_{4}$ hypersensitivity in mitotic cells. Hatched arrows show reactive bases in non-mitotic cells which may be due to paused RNA polymerase. Stippled arrow in $\mathbf{b}$ indicates a constitutive $\mathrm{KMnO}_{4}$ hyperactive site. 
phase of the cell cycle. This approach has identified and mapped melted DNA at promoters bearing paused RNA polymerases ${ }^{13}$ and at other sites binding single-strand-specific factors ${ }^{10,11}$. The c-myc $\mathrm{P} 2$ promoter, a major region of $\mathrm{S} 1$ sensitivity in isolated nuclei, was analysed with $\mathrm{KMnO}_{4}$ during mitosis in synchronized cells. In parallel, in vivo dimethylsulphate (DMS) footprinting of the hsp70 promoter was used to monitor displacement of conventional double-stranded DNA binding proteins ${ }^{6}$. HeLa cells were treated with nocodazole for eight hours ${ }^{6}$ (which synchronizes cells at metaphase), separated by shake-off into mitotic and non-mitotic cells, incubated for $30 \mathrm{~min}$ at either $37^{\circ} \mathrm{C}$ or $43^{\circ} \mathrm{C}$ (for analysis of the hsp70 promoter), and treated in vivo with either DMS or $\mathrm{KMnO}_{4}$ (ref. 9). Purified DNA was subjected to LM-PCR using primers that allowed visualization of the top strand of the human $c-m y c$ gene in the vicinity of the $\mathrm{P} 2$ transcription start site.

$\mathrm{KMnO}_{4}$ reactions revealed unexpected mitosis-specific unwinding of the $m y c$ P2 TATA-box/start-site region (Fig. 1a; compare lanes $2,3$ with 4,5$)$. These changes were not apparent by DMS footprinting (Fig. 1a; compare lanes 7, 8 with 9, 10). Similar changes were noted in mitotic cells prepared without nocodazole and hence were not caused by blocking the cell cycle (data not shown). Controls confirmed that cells were properly synchronized (mitotic index of $>95 \%$ ), that dramatic mitotic displacement of the conventional double-stranded DNA-binding proteins Sp1 and HSF (heat-shock factor) from the $h s p 70$ promoter proceeded as described $^{6}$, and that upregulation of in vivo binding by HSF (and Sp1 to a lesser extent) occurred upon heat shock only in nonmitotic cells (data not shown).

The $h s p 70$ TATA-box region ${ }^{6}$ was examined during mitosis. Like the $c-m y c$ P2 promoter, the $h s p 70$ TATA box experienced a conformational change that was specific for mitosis (Fig. 1b; compare lanes 2, 3 with 4, 5; and lanes 7, 8 with 9, 10). Again, these changes were not seen with DMS (data not shown). Not all TATA boxes
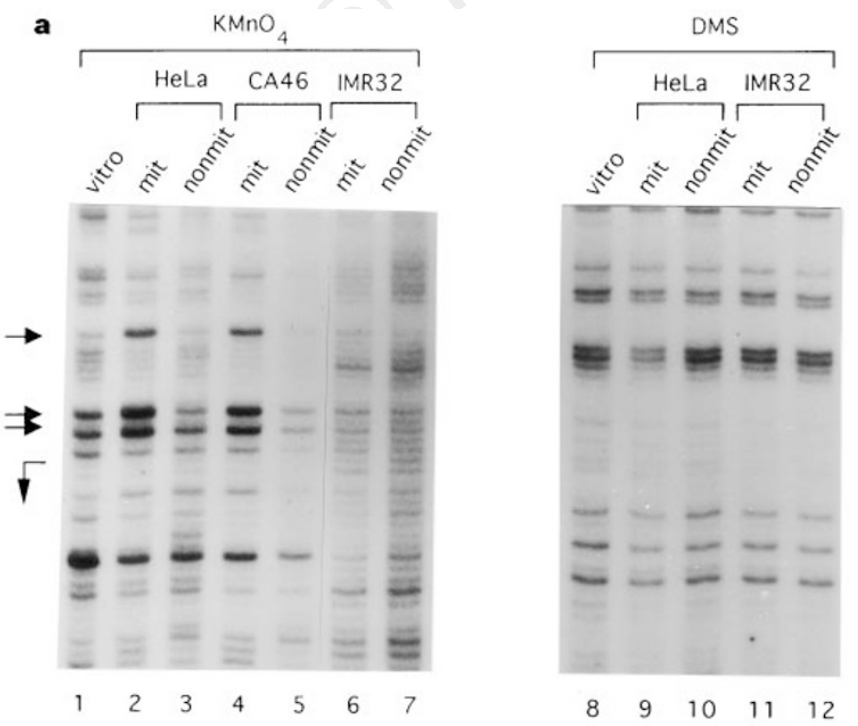

Figure 2 a, The c-myc P2 TATA-box region is not conformationally perturbed during mitosis when not expressed in IMR32 nucleoblastoma cells. Genomic DNA in vitro or intact synchronized HeLa, CA46, or IMR32 cells were treated with $\mathrm{KMnO}_{4}$ (lanes 1-7) or DMS (lanes 8-12) and analysed by LM-PCR. b, the hsp70 TATA box region is mitotically marked in ImR32 neuroblastoma cells. DNA reacted in vivo with $\mathrm{KMnO}_{4}$ (lanes $1-4$ ) or DMS (lanes 5,6 ) from synchronized IMR32 neuroblastoma and HeLA cells was used to assess marking of the bottom strand of the hsp70 promoter region via LM-PCR. were mitotically distorted, because no changes occurred at c-myc P1 (Fig. 1c; compare lanes 1, 2 with 3,4), which also appeared to be vacant as judged by DMS footprinting. Perhaps the conformational changes at the $h s p 70$ and $c-m y c$ promoters marked these genes for transcriptional restart following mitosis. If so, the proximal promoter region of non-expressed genes should be unreactive with $\mathrm{KMnO}_{4}$ during mitosis. As predicted, neither strand of the silent $\beta$-globin gene showed mitosis-specific changes (Fig. 1d, compare lanes 2,3 with 4,5 , and lanes 7,8 with 9, 10). Thus, stable gene activity correlated with perturbation of the TATA box during mitosis.

If mitotic TATA-box marking were linked to the maintenance of gene expression, then no unwinding at the c-myc P2 TATA-box region should occur when $c-m y c$ transcription is repressed. In IMR32 neuroblastoma cells overexpressing $\mathrm{N}-m y c$, the c-myc locus is shut off and $c-m y c$ RNA is undetectable ${ }^{10}$. No change in DNA conformation of the c-myc $\mathrm{P} 2$ proximal promoter region was detected with $\mathrm{KMnO}_{4}$ (Fig. 2a) or DMS (Fig. 2a, right), either in mitotic or non-mitotic IMR32 cells (Fig. 2a; compare lanes 6, 7 with $2,3)$, indicating that mitosis-specific tagging of this start site was linked to gene expression. Likewise, no $\mathrm{KMnO}_{4}$ hypersensitivity was induced on the complementary strand (Fig. 2a, right). DMS reactions in HeLa and IMR32 cells were indistinguishable (Fig. 2a, lanes 8-12). The lymphoma cell line CA46, which expresses c-myc, was also mitotically marked at P2 (Fig. 2a, lanes 4 and 5).

The lack of mitosis-specific marking of c-myc in IMR32 cells might simply have been due to a cell-line-specific defect in whatever machinery was required for unwinding. We therefore tested the mitotic $\mathrm{KMnO}_{4}$ reactivity of the $h s p 70$ gene, which is expressed in both IMR32 and HeLa cells. The hsp70 TATA-box region was similarly tagged in neuroblastoma cells (Fig. 2b, lanes 1 and 2) and HeLa cells (Fig. 2b, lanes 3 and 4), indicating that the mechanism for TATA-box unwinding is intact in IMR32 cells; therefore the

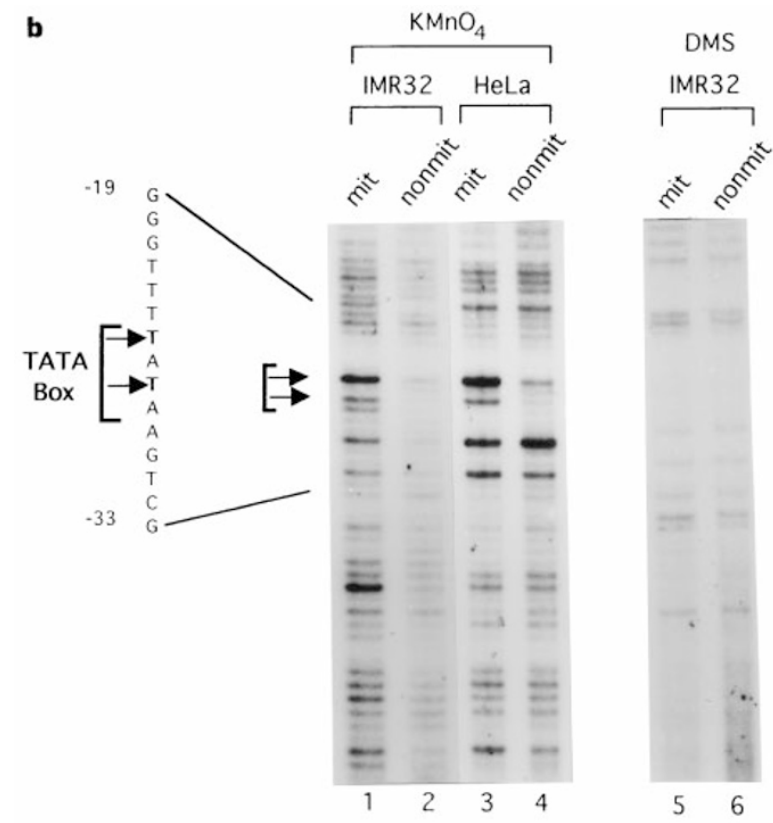

Sp 1

ggegggtcte egtgacgact tataaacec caggggeaag eggtceggat aacggetagc ccgcccagag geactgetga aTaTtttggg gtccecgttc gecaggecta ttgcegatco $-48 \quad-8$ 
lack of unwinding at the $\mathrm{c}-m y c \mathrm{P} 2$ promoter in IMR32 was probably linked to the absence of $\mathrm{c}-m y c$ transcription.

Genes lacking TATA boxes, including some 'housekeeping' genes, must also be restarted after mitosis. If mitotic marking contributes generally to re-expression, then expressed TATA-less genes such as the ets-2 protooncogene ${ }^{14}$ should display mitotic perturbation near their initiation sites. Indeed, several nucleotides at the ets-2 start site and in the adjacent upstream sequence were mitotically reactive with $\mathrm{KMnO}_{4}$ (Fig. 3, arrows), whereas downstream residues were reactive only in non-mitotic cells (Fig. 3, arrowheads), which is consistent with transcriptional melting. Furthermore, a TATA-less promoter that is silent in HeLa cells, that for the terminal deoxynucleotidyl transferase (TdT) gene ${ }^{15,16}$ was devoid of mitosisspecific characteristics (data not shown).

What are the molecular requirements for placement of mitotic bookmarks? The diversity of affected promoters and the association with gene activity argues strongly against specific sequence recognition as the basis for mitotic marking. The correlation of mitotic tags with the activity of the c-myc, $h s p 70$, ets-2, TdT or $\beta$-globin genes indicates that the conformational distortion is not due solely to chromosome condensation. However, the mitotic mark might represent buckling of naked promoter DNA, vacated during metaphase, under mechanical stress, but such a mechanism should have strained both c- $m y c$ promoters equally. Alternatively, melting might require a protein factor or cofactor. If this hypothetical protein"s half-life were sufficiently short, then the metaphase-specific $\mathrm{KMnO}_{4}$ hyperactive sites at the $c-m y c$ P2 promoter should decay with cycloheximide treatment. Therefore, nocodazole-synchronized mitotic HeLa cells were divided into two aliquots and incubated for varying lengths of time, with or without $25 \mu \mathrm{g} \mathrm{ml}^{-1}$ cycloheximide. Cycloheximide- and mock-treated cells were reacted in vivo in the presence of nocodazole with $\mathrm{KMnO}_{4}$ for LM-PCR analysis. A cycloheximide-induced decrease in mitosis-specific $\mathrm{KMnO}_{4}$ reactivity (relative to mock-treated cells) at the $\mathrm{c}-m y c \mathrm{P} 2$ promoter was first detected $3 \mathrm{~h}$ after cycloheximide treatment (Fig. 4a; compare lanes 5 and 6 with 3 and 4) and was clearly evident at $4 \mathrm{~h}$ (Fig. 4a, lanes 7 and 8). Also potentially turning over in this experiment, however, were proteins required for chromosome condensation; the resulting chromosome decompaction could compromise interpretation of in vivo $\mathrm{KMnO}_{4}$ analysis. To exclude these complications, both mock- and cycloheximidetreated cells from the 4 -h time point were fixed, stained ${ }^{17}$ and microscopically examined; no changes in chromosome morphology induced by cycloheximide treatment were evident (data not shown). This experiment supports the existence of a protein required for the maintenance of the mitosis-specific mark at the c- $m y c$ P2 start site.

These results provide in vivo evidence that a protein is required for mitosis-specific melting of the c-myc P2 start site. In vitro evidence for such a protein was sought by testing the salt-extractability of this factor from purified mitotic chromosomes. Nocodazole-arrested mitotic HeLa cells were lysed in hypotonic buffer, condensed chromosomes were centrifugally purified and then extensively washed with buffers of increasing ionic strength. Washed mitotic chromosomes were then treated with $\mathrm{KMnO}_{4}$ and analysed by LMPCR. The mitotic mark resisted extraction with $10 \mathrm{mM} \mathrm{NaCl}$ (Fig. 4b, lane 1), $200 \mathrm{mM} \mathrm{NaCl}$ (Fig. 4b, lane 2) and $300 \mathrm{mM} \mathrm{NaCl}$ (data not shown). Extraction with $400 \mathrm{mM} \mathrm{NaCl}$ yielded a pattern of $\mathrm{KMnO}_{4}$ hypersensitive site very similar to that of non-mitotic cells (Fig. 4b; compare lanes 3 and 4). A mitotic marker was extracted, but $400 \mathrm{mM} \mathrm{NaCl}$ is also sufficient to mobilize nucleosomes and potentially alter other features peculiar to the mitotic chromatin of active genes.

Re-addition of the $0.4 \mathrm{M} \mathrm{NaCl}$ extract to the salt-washed mitotic chromosomes failed to restore the mitotic marker. It is unlikely that simple sequence recognition mediates direct formation of marker complexes at active promoters. If the marker itself instructs genes to

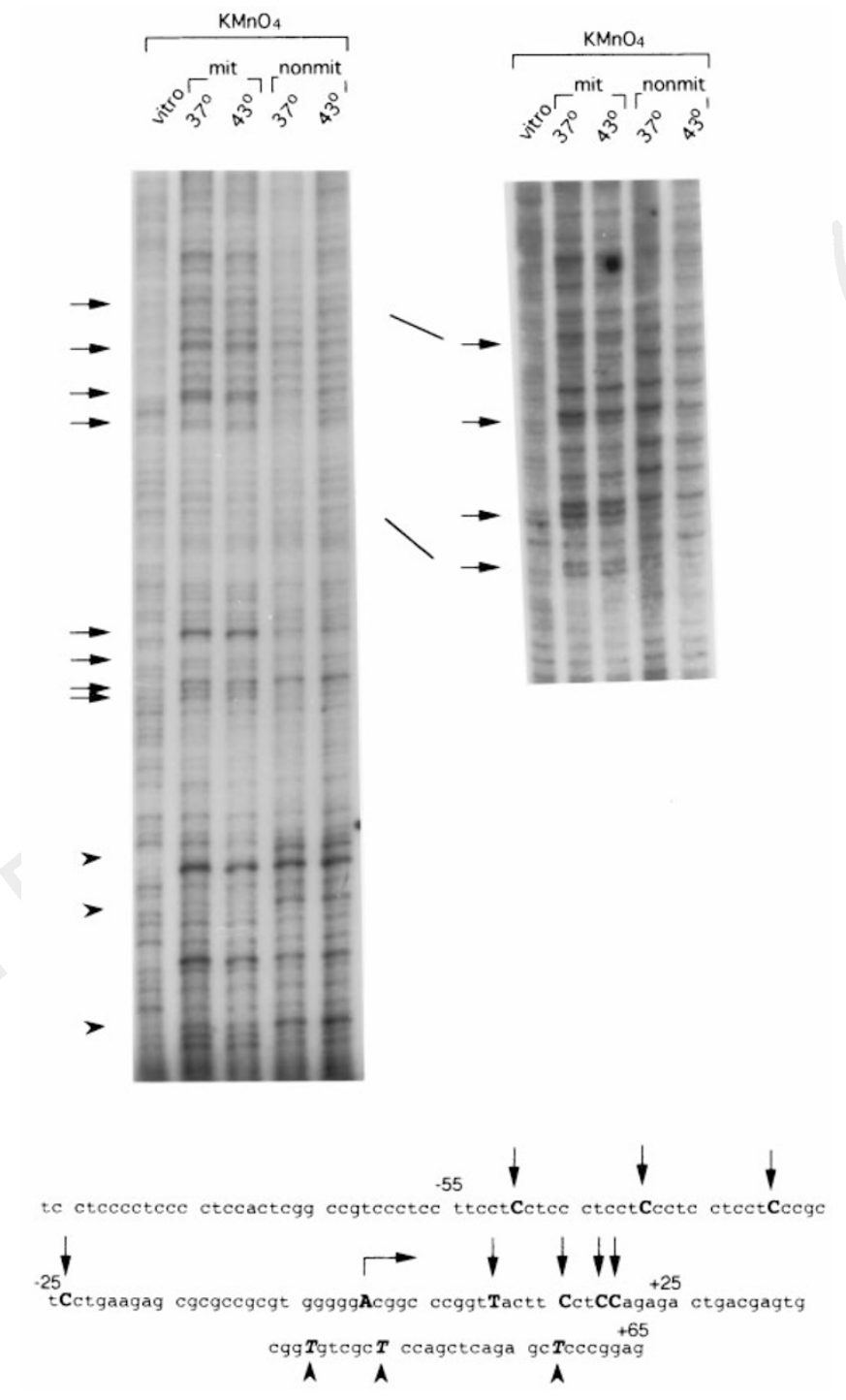

Figure 3 The ets-2 start site is marked during mitosis. Left, bases mitotically reactive with $\mathrm{KMnO}_{4}$ are indicated with arrows; arrowheads indicate bases selectively reactive in non-mitotic cells. Right, longer run of sequences upstream of -20 . Bottom, summary of reactive bases; bent arrow indicates the start-site $(+1)$.

be post-mitotically expressed, then removal of the marker should convert expressed genes to the default silent state. In the absence of transcriptional activity, reconstitution of the marker would not occur. Alternatively, the mitotic marker may act as an accessory factor to maintain a segment of DNA already configured for transcription, ready for reoccupancy by the transcription machinery. In this scheme, accurate reconstitution of the mitotic marker would be achievable unless the salt treatment disrupted native mitotic chromatin or removed cofactors.

The mitosis-specific $\mathrm{KMnO}_{4}$ hypersensitivity indicates a nidus of single-stranded DNA at start sites, perhaps stabilized by bound protein. Two features of single-stranded DNA might facilitate transcription restart. First, nucleosomes, which might otherwise obstruct the promoter, have a reduced affinity for single-stranded $\mathrm{DNA}^{18}$. Second, the deformability of single-stranded DNA to flexural and torsional stress ${ }^{19}$ facilitates the assembly of the transcription complex, especially if the returning TFIID or other basal components recognized the bookmarker ${ }^{7}$. In vivo footprinting indicates that other single-stranded DNA-binding proteins, hnRNP 


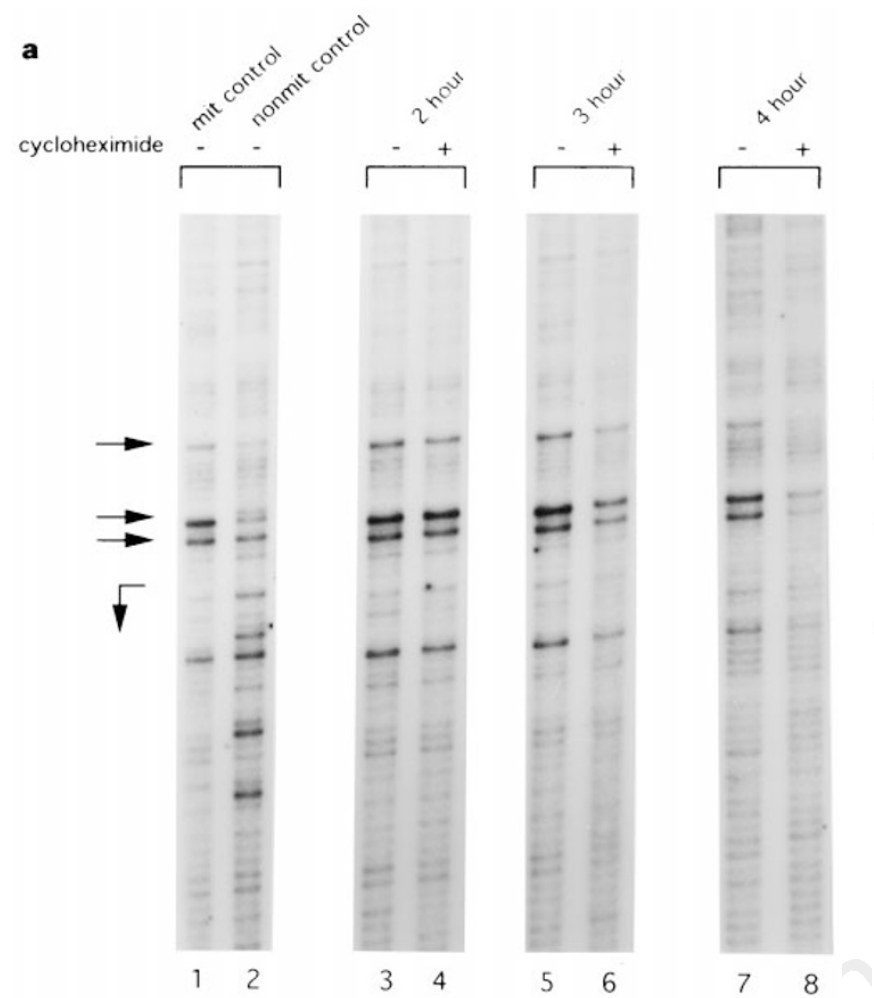

b

b mitotic chromatin salt extractions $\therefore v_{0}^{\circ} \approx$

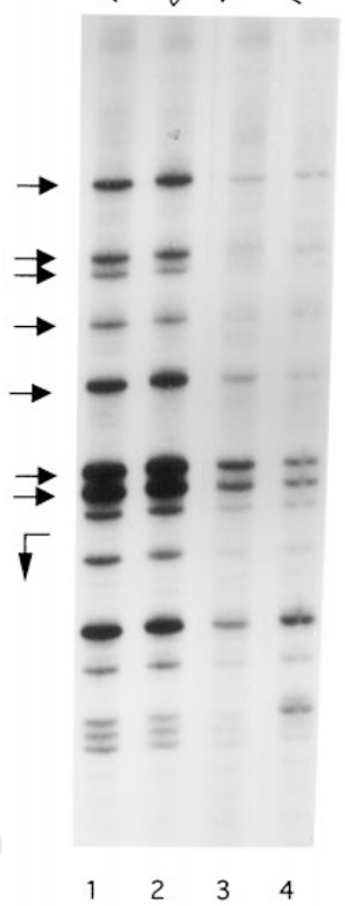

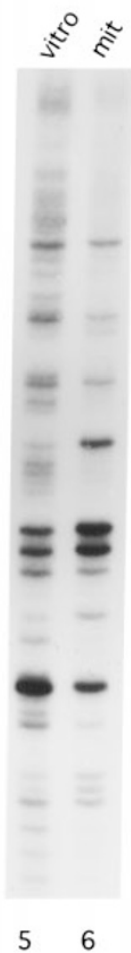

Figure 4 Protein requirement for the melting of the c-myc P2 TATA-box region during mitosis. a, Nocodazole-arrested mitotic HeLa cells were shaken off and separated into two nocodazolecontaining flasks, one with cycloheximide, one without cycloheximide. At various times, samples were treated in vivo with $\mathrm{KMnO}_{4}$, and purified DNA was analysed by LM-PCR using primers that visualized the top strand of the c-myc P2 promoter. b. Factor(s) required for mitosisspecific c-myc P2 promoter $\mathrm{KMnO}_{4}$ hypersensitivity is saltextractable. HeLa cells were treated with nocodazole for $8 \mathrm{~h}$ and mitotic cells were shaken off. Cells were then hypotonically lysed and mitotic chromosomes purified by centrifugation. Chromosomes were then extracted with increasing concentrations of $\mathrm{NaCl}$, and treated with $\mathrm{KMnO}_{4}$. The top strand of the c-myc P2 promoter was then analysed by LM-PCR.
$\mathrm{K}$ and $\mathrm{FBP}^{9}$, remain bound to the human $\mathrm{c}-m y c$ promoter during mitosis (data not shown) when the single-stranded character of bulk chromatin increases 10 -fold ${ }^{12}$. Single-stranded DNA and associated factors may therefore be important for mitosis.

What is the source of single-stranded DNA during mitosis? Possibly transcription; melted DNA at promoter start sites in this scheme is stabilized by a factor, perhaps also interacting with the transcription machinery, just before $M$ phase. Persistence of the marker through mitosis may require sustained torque. The requirement for topoisomerase I activity in chromosome condensation indicates that torsional strain is indeed present during compaction $^{20}$. Recruitment of the cellular transcription machinery to genes marked by stressed DNA could be important to re-establish the correct range of expressed genes.

\section{Methods}

Ligation-mediated PCR. In vivo footprinting was done as described ${ }^{21}$. Primers for LM-PCR analysis of the top strand of the c-myc P2 region were: TAGCCCCCTATTCGCTC, CCCCTATTCGCTCCGGATCTCCC and TTCGCTCCGGATCTCCCTTCCCAGGA. Primers for LM-PCR analysis of the top strand of c-myc P1 were: TCTCGAGGCAGGAGGGG, CGAGGCAGGAGGGGAGCCAGGGAC and GGGAGGAGGGGAGCCAGGGACGGCCGG. Primers for analysis of the bottom strand of the globin TATA-box region were: CACTTAGACCTCACCCTG. GACCTCACCCTGTCCAGCCACAC and CTGTGGAGCCACACCCTAGGGTTGGCC; primers for the top strand of globin were: GTCAGGTGCACCATGGTG, TGCACCATGGTGTCTGTTTGAGG and GTGTCTGTTTGAGGTTGCTAGTGAAC. Primers for the strand strand of the ets-2 promoter were: CTCCGGGAGCTCTGAGC, CGGGAGCTCTGAGCTGGAGCGAC and GAGCTCTGAGCTGGAGCGACACCGCA.

LM-PCR analysis of mitotic chromosomes. Washed HeLa cells were Dounce-homogenized in $10 \mathrm{mM}$ Tris, $\mathrm{pH} 8.0,10 \mathrm{mM} \mathrm{KCl}$. Mitotic chromosomes were pelleted by a 2-min spin in the microfuge and washed with a buffer containing $10 \mathrm{mM}$ Tris, $\mathrm{pH} 8.0,1.5 \mathrm{mM} \mathrm{MgCl}_{2}, 0.5 \mathrm{mM}$ EDTA, plus the indicated amounts of salt. LM-PCR analysis then proceeded as with intact cells. Fixing and staining of mitotic chromosomes was done as before ${ }^{17}$.
Received 27 January; accepted 9 June 1997.

1. Alberts, B. et al. Molecular Biology of the Cell (Garland, New York and London, 1994).

2. Weintraub, H. Assembly and propagation of repressed and depressed chromosomal states. Cell 42, 705-711 (1985).

3. Martienssen, R. A. \& Richards, E. J. DNA methylation in eukaryotes. Curr. Opin. Genet. Dev. 5, 234242 (1995).

4. Groudine, M. \& Weintraub, H. Propagation of globin DNAase I-hypersensitive sites in absence of factors required for induction: a possible mechanism for determination. Cell 30, 131-139 (1982).

5. Liu, B. \& Alberts, B. M. Head-on collision between a DNA replication apparatus and RNA polymerase transcription complex. Science 267, 1131-1137 (1995).

6. Martinez-Balbas, M. A., Dey, A., Rabindran, S. K., Ozato, K. \& Wu, C. Displacement of sequencespecific transcription factors from mitotic chromatin. Cell 83, 29-38 (1995).

7. Segil, N., Guermah, M., Hoffmann, A., Roeder, R. G. \& Heintz, N. Mitotic regulation of TFIID: inhibition of activator-dependent transcription and changes in subcellular localization. Genes Dev. 10, 2389-2400 (1996)

8. Larsen, A. \& Weintraub, H. An altered DNA conformation detected by S1 nuclease occurs at specific regions in active chick globin chromatin. Cell 29, 609-622 (1982).

9. Michelotti, E. F., Michelotti, G. A., Aronsohn, A. \& Levens, D. Heterogeneous nuclear ribonucleoprotein K is a transcription factor. Mol. Cell. Biol. 16, 2350-2360 (1996).

10. Michelotti, G. A. et al. Multiple single-stranded cis elements are associated with activated chromatin of the human c-myc gene in vivo. Mol. Cell. Biol. 16, 2656-2669 (1996).

11. Duncan, R. et al. A sequence-specific, single-strand binding protein activates the far upstream element of $c-m y c$ and defines a new DNA binding motif. Genes Dev. 8, 465-480 (1994).

12. Juan, G., Pan, W. \& Darzynkiewicz, Z. DNA segments sensitive to single-strand-specific nucleases are present in chromatin of mitotic cells. Exp. Cell Res. 227, 197-202 (1996).

13. Giardina, C., Perez-Riba, M. \& Lis, J. T. Promoter melting and TFIID complexes on Drosophila genes in vivo. Genes Dev. 6, 2190-2200 (1992).

14. Mavrothalassitis, G. W., Watson, D. K. \& Papas, T. The human ETS-2 gene promoter: molecular dissection and nuclease hypersensitivity. Oncogene 5, 1337-1342 (1990).

15. Koiwai, O. \& Morita, A. Isolation of a putative promoter region for human terminal deoxynucleotidyltransferase gene. Biochem. Biophys. Res. Commun. 154, 91-100 (1988).

16. Bhaumik, D. et al. Identification of a tripartite basal promoter which regulates human terminal deoxynucleotidyl transferase gene expression. J. Biol. Chem. 269, 15861-15867 (1994).

17. Schweizer, D. \& Ambros, P. F. Chromosome Analysis Protocols 1-97-112 (Humana, Totowa, 1994).

18. Bonne-Andrea, C., Wong, M. L. \& Alberts, B. M. In vitro replication through nucleosomes without histone displacement. Nature 343, 719-726 (1990).

19. Kahn, J. D., Yun, E. \& Crother, D. M. Detection of localized DNA flexibility. Nature 368, 163-166 (1994).

20. Castano, I. B., Brzoska, P. M., Sadoff, B. U., Chen, H. \& Christman, M. F. Mitotic chromosome condensation in the rDNA requires TRF4 and DNA topoisomerase I in Saccharomyces cerevisiae. Genes Dev. 10, 2546-2576 (1996).

21. Mueller, P. R. \& Wold, B. In vivo footprinting of a muscle specific enhancer by ligation mediated PCR. Science 246, 780-786 (1989).

Acknowledgements. We thank L. Liotta, C. Wu, S. Mackem and M. Reitman for critical review of the manuscript.

Correspondence and requests for materials should be addressed to D.L. 